\title{
Intelligent Resource Management in the context of a Microgrid of Smart Buildings
}

\author{
Sérgio Ramos ${ }^{1}$, João Soares ${ }^{1}$, Zahra Foroozandeh ${ }^{1}$, Inês Tavares ${ }^{1}$, António Gomes ${ }^{1}$ \\ ${ }^{1}$ GECAD - Research Group on Intelligent Engineering and Computing for Advanced Innovation and Development \\ Polytechnic of Porto (ISEP/IPP) \\ Rua Dr. António Almeida, 431, 4200-072, Porto, Portugal \\ e-mail: scr@isep.ipp.pt, jan@isep.ipp.pt, zah@isep.ipp.pt, ivtav@isep.ipp.pt, aag@isep.ipp.pt
}

\begin{abstract}
This paper presents intelligent energy management with penetration of Distributed Generation (DG) and Electric Vehicles (EVs). The envisaged problem is a hard combinatorial Mixed-Integer Linear Programming (MILP) problem due to the continuous, discrete, and binary variables. The proposed problem focuses on minimizing the electricity cost. The MILP problem is modelled with a deterministic technique, namely TOMLAB, using a CPLEX solver. This paper includes a realistic case study using data collected from two real buildings facilities (consumption and generation profiles).
\end{abstract}

Keywords. Buildings, Demand Response, Electric Vehicles, Energy Resources Management.

\section{Nomenclature}

\begin{tabular}{|ll|}
\hline Indices & \multicolumn{1}{c|}{ Description } \\
\hline$I$ & Index of DG units \\
$T$ & Index of periods \\
$L$ & Index of loads \\
$S$ & Index of external suppliers \\
$V$ & Index of EVs \\
$E$ & Index of ESSs \\
$M$ & Index of energy buyers \\
\hline Parameter & \\
\hline$N_{\mathrm{DG}}$ & Total number of distributed generator \\
$N_{\mathrm{L}}$ & Total number of loads \\
$N_{\mathrm{ST}}$ & Total number of storage units \\
$N_{\mathrm{S}}$ & Total number of external suppliers \\
$N_{\mathrm{V}}$ & Total number of EVs \\
$N_{E}$ & Total number of ESSs \\
$N_{\mathrm{M}}$ & Total number of energy buyers \\
$c_{\mathrm{DG}(t)}^{\mathrm{I}}$ & Generation price of DG unit I in $\mathrm{t}$ \\
$c_{\mathrm{NSD}(t)}^{\mathrm{L}}$ & Non-supplied demand price of load L in $\mathrm{t}$ \\
$c_{\mathrm{S}(t)}^{\mathrm{S}}$ & Energy price of external supplier S in $\mathrm{t}$ \\
&
\end{tabular}

\begin{tabular}{|c|c|}
\hline$c_{L D R(L, t)}$ & Demand response cost of load $\mathrm{L}$ in $\mathrm{t}$ \\
\hline$M P_{\mathrm{S}(t)}^{\mathrm{M}}$ & Price energy sale to market $\mathrm{M}$ in $\mathrm{t}$ \\
\hline$P_{\mathrm{DGmL}(t)}^{\mathrm{I}}$ & $\begin{array}{l}\text { Minimum active power of dispatchable DG } \\
\text { unit I in period } t\end{array}$ \\
\hline$P_{\mathrm{DGML}(t)}^{\mathrm{I}}$ & $\begin{array}{l}\text { Maximum active power of dispatchable DG } \\
\text { unit } \mathrm{I} \text { in period } \mathrm{t}\end{array}$ \\
\hline$P_{\mathrm{SML}(t)}^{\mathrm{S}}$ & Minimum active power of supplier $\mathrm{S}$ in $\mathrm{t}$ \\
\hline$P_{\mathrm{SMML}(t)}^{\mathrm{S}}$ & Maximum active power of supplier $\mathrm{S}$ in $\mathrm{t}$ \\
\hline$\eta_{c}^{\mathrm{E}}$ & Charging efficiency of ESS E (\%) \\
\hline$\eta_{d}^{\mathrm{E}}$ & Discharging efficiency of ESS E (\%) \\
\hline$P_{\mathrm{DL}(t)}^{\mathrm{E}}$ & Maximum discharge rate of ESS $\mathrm{E}$ in $\mathrm{t}$ \\
\hline$P_{\mathrm{CL}(t)}^{\mathrm{E}}$ & Maximum charge rate of ESS E in $t$ \\
\hline$E_{\mathrm{BC}}^{\mathrm{E}}$ & Maximum energy stored allowed by ESS \\
\hline$E_{\mathrm{MC}(t)}^{\mathrm{E}}$ & Minimum energy stored required ESS in $t$ \\
\hline$\eta_{c}^{\mathrm{V}}$ & Charging efficiency of EV V \\
\hline$E_{\mathrm{T}(t)}^{\mathrm{V}}$ & Forecasted energy demand for EV trip in $\mathrm{t}$ \\
\hline$P_{\mathrm{CL}(t)}^{\mathrm{V}}$ & Maximum active discharge rate of $\mathrm{EV}$ in $\mathrm{t}$ \\
\hline$E_{\mathrm{MC}(t)}^{\mathrm{V}}$ & Minimum energy stored required in $\mathrm{EV}$ in $\mathrm{t}$ \\
\hline$P_{\mathrm{LDRML}(t)}^{\mathrm{L}}$ & Maximum limit of power reduction of load in $t$ \\
\hline$X_{\mathrm{DR}(t)}^{\mathrm{L}}$ & $\begin{array}{l}\text { Binary variable representing DR event state of } \\
\text { load in } t\end{array}$ \\
\hline$P_{\text {LDRMT }(t)}^{\mathrm{L}}$ & $\begin{array}{l}\text { Maximum limit of periods to use the power } \\
\text { reduction of load }\end{array}$ \\
\hline$P_{\mathrm{BSML}(t)}^{\mathrm{M}}$ & Maximum energy bid in market $\mathrm{M}$ in $\mathrm{t}$ \\
\hline$P_{\mathrm{BSmL}(t)}^{\mathrm{M}}$ & Minimum energy bid in market $\mathrm{M}$ in $\mathrm{t}$ \\
\hline
\end{tabular}

\section{Introduction}

In the context of the buildings, a new opportunity emerges and the consumer becomes a prosumer, being 
able to adapt the consumption depending on own generated power, selling the surplus power, or buying the missing power, according to the needs of the moment [12]. The new paradigm showed the consumer with active participation in the grid environment and changing own use' habits caused by the intensive use of RES of intermittent nature: the balance between consumption and generation [3].

Currently, the final consumer cannot be considered just a load, the reality is they are active actors on the electrical network, where it is necessary to make the management of their energy resources, including their loads, generators units, Energy Storage Systems (ESSs) and Electric Vehicles (EVs). In this context, a building should include three main elements: an internal communication network, intelligent control systems, and home automation [4]. Moreover, Home Management Systems (HMS) should be able to effectively manage consumption, distributed generation, and participation in Demand Response (DR) events, such as dynamic energy tariffs [5]. Also, HMS should consider, the minimization of the energy bill and the required comfort levels in the operation context [6].

This paper presents a building energy management model that includes DR programs, EVs, and DG. The envisaged problem is a hard combinatorial Mixed-Integer Linear Programming (MILP) problem due to the continuous, discrete, and binary variables. The proposed problem focuses on minimizing the electricity cost. The MILP is implemented with a deterministic technique, namely TOMLAB, using a CPLEX solver. A case study is presented using real data collected from two real building facilities (consumption and generation profiles). The case study accommodates also EVs and ESS, to verify the feasibility of the HMS algorithm implemented.

This paper is organized as follows: after this introductory section III presents a short review on energy management. In section IV the mathematical formulation of the Energy Resources Management problem is proposed, section $\mathrm{V}$ presents the case study, and finally, section VI the conclusions.

\section{Short Review}

Several studies have been reported in the recent literature about home energy management (HEM) systems and energy resources management (ERM). Reference [7] presents a price-based HEM framework that incorporates the priority of different appliances in the optimization model. To do this, the value of the lost load is determined for each appliance, according to common time-varying tariffs for residential customers, i.e., time of use (TOU) and inclining block rate (IBR). The objective function is to minimize the customer's energy and reliability costs for the next day. In [8] is presented a HEM algorithm for managing household power-incentive appliances. The algorithm can control selected appliances and keep the total household power consumption below a certain limit while considering customer preferences and allowing the customer more flexibility to operate their appliances. A distributed algorithm for a HEM system is implemented in [9]. This algorithm finds the optimal operating times for the electric appliances and their corresponding energy consumptions by minimizing the overall cost operation. The authors enforce realistic constraints on the operation of the appliances by categorizing them into two different classes. An optimal power scheduling method for DR in HEM is presented in [10]. The objective is to reduce the electricity cost and the power peak-to-average ratio. Two different kinds of home appliances are considered, namely, automatically operated appliances and manually operated appliances. The authors assume that the automatically operated appliances are smart home appliances.

A demonstration of the HEM system for managing end-use appliances is presented in [11]. The objective of this demonstration is to evaluate the HEM operation performance, in particular how each load performs when being controlled by the HEM unit. A demand-side management strategy that was integrated into the HEM system (HEMS) is presented in [12]. The work presents the implementation of HEMS using a multi-agent system for smart homes which allows consumers to know the amount of electricity used or metering devices and allow them to make changes when it is needed. In Reference [13] an energy management system is proposed to reduce power demands and energy costs of a residential building. The resources include the use of PV generation, BESS usage, and the schedule of EV's charging and discharging process. Finally, in [14], a Multi-Objective Mixed-Binary Linear Programming (MOMBLP) formulation was implemented to minimize the total energy consumption cost and peak load consumption in the residential building context.

\section{ERM Platform}

The ERM methodology optimizes the distributed energy resources that are available in a microgrid (MG) with two residential buildings. It considers all the available resources: DG, storage units, and DR, and supports the negotiation with external players. The goal is to satisfy demand aiming at obtaining the minimum electricity cost. Before the presented the model, the needed variable are summarized in the following table.

\begin{tabular}{cl}
\hline Variables & \multicolumn{1}{c}{ Description } \\
\hline$P_{\mathrm{DG}(t)}^{\mathrm{I}}$ & Power generation of $I$ unit in period $t$ \\
$P_{\mathrm{S}(t)}^{\mathrm{S}}$ & Power generation of external supplier $S$ in $t$ \\
$P_{\mathrm{LDR}(t)}^{\mathrm{L}}$ & $\begin{array}{l}\text { Demand response program active power } \\
\text { activated for load } L \text { in period } t\end{array}$ \\
$P_{\mathrm{D}(t)}^{\mathrm{E}}$ & Power discharge of ESS unit $E$ in $t$ \\
$P_{\mathrm{C}(t)}^{\mathrm{E}}$ & Power charge of ESS unit $E$ in $t$ \\
$P_{\mathrm{C}(t)}^{\mathrm{V}}$ & Power charge of EV $V$ in period t \\
$P_{\mathrm{NSD}(t)}^{\mathrm{L}}$ & Non-supplied demand for load $L$ in $t$ \\
$P_{\mathrm{L}(t)}^{\mathrm{L}}$ & Power demand of load $L$ in period $t$
\end{tabular}




\begin{tabular}{ll}
\hline$X_{\mathrm{DG}(t)}^{\mathrm{I}}$ & Binary variable of DG of unit $I$ in $t$ \\
$X_{\mathrm{S}(t)}^{\mathrm{S}}$ & Binary variable of supplier $S$ in $t$ \\
$X_{\mathrm{ESS}(t)}^{\mathrm{E}}$ & Binary variable of discharge ESS $E$ in $t$ \\
$Y_{\mathrm{EES}(t)}^{\mathrm{E}}$ & Binary variable of charge of ESS $E$ in $t$ \\
$E_{\mathrm{S}(t)}^{\mathrm{E}}$ & Energy stored in ESS $E$ in period $t$ \\
$E_{\mathrm{S}(t)}^{\mathrm{V}}$ & Energy stored in EV $V$ in period $t$ \\
$C$ & Total operation cost \\
\hline
\end{tabular}

\section{A. Objective function}

The envisaged problem is a hard combinatorial Mixed-Integer Linear Programming (MILP) problem due to the continuous, discrete, and binary variables. The managing entity focuses on minimizing the cost (1), the goal is to use cheaper resources. The MILP is implemented in TOMLAB [15], which is an advanced optimization toolbox for MATLAB [16], using a CPLEX solver. Function $C$ (1) represents the operation cost of the resources managed by the $\mathrm{SB}$ aggregator. It considers the cost with DG and external suppliers. The MG can receive his income from three sources, as illustrated in (1): the revenue from the energy to sell to the electricity market, the revenue from DR programs, and the revenue penalization with non-supplied demand.

$$
\begin{gathered}
\text { Minimize } C= \\
\sum_{t=1}^{T}\left[\begin{array}{c}
\sum_{I=1}^{N_{\mathrm{DG}}} P_{\mathrm{DG}(t)}^{\mathrm{I}} \cdot c_{\mathrm{DG}(t)}^{\mathrm{I}}+\sum_{S=1}^{N_{\mathrm{S}}} P_{\mathrm{S}(t)}^{\mathrm{S}} \cdot c_{\mathrm{S}(t)}^{\mathrm{S}}- \\
\sum_{L=1}^{N_{\mathrm{L}}} P_{\mathrm{LDR}(t)}^{\mathrm{L}} \cdot c_{\mathrm{LDR}(t)}^{\mathrm{L}}-\sum_{L=1}^{N_{L}} P_{\mathrm{NSD}(t)}^{\mathrm{L}} \cdot c_{\mathrm{NSD}(t)}^{\mathrm{L}}- \\
\sum_{M=1}^{N_{\mathrm{M}}} P_{\mathrm{S}(t)}^{\mathrm{M}} \cdot M P_{\mathrm{S}(t)}^{\mathrm{M}}
\end{array}\right]
\end{gathered}
$$

\section{B. Model constraints \\ 1) Energy balance constraint}

The balance constraint (2) is included in the proposed model. The amount of generated energy should be equal to the amount of consumed energy at a given moment $t$ :

$$
\begin{gathered}
\sum_{I=1}^{N_{D G}} P_{\mathrm{DG}(t)}^{\mathrm{I}}+\sum_{S=1}^{N_{S}} P_{\mathrm{S}(t)}^{\mathrm{S}}+\sum_{L=1}^{N_{L}}\left(P_{\mathrm{NSD}(t)}^{\mathrm{L}}+P_{\mathrm{LDR}(t)}^{\mathrm{L}}-P_{\mathrm{L}(t)}^{\mathrm{L}}\right)- \\
\sum_{V=1}^{N_{V}} P_{\mathrm{C}(t)}^{\mathrm{V}}+\sum_{E=1}^{N_{E}}\left(P_{\mathrm{D}(t)}^{\mathrm{E}}-P_{\mathrm{C}(t)}^{\mathrm{E}}\right)-\sum_{M=1}^{N_{M}} P_{\mathrm{S}(t)}^{\mathrm{M}}=0, \quad \forall t
\end{gathered}
$$

\section{2) Generation}

A binary variable is used to represent the commitment status of dispatchable DG units. A value of 1 means that the unit is connected. Maximum and minimum limits for active power in each period $t$ can be formulated as:

$$
X_{\mathrm{DG}(t)}^{\mathrm{I}} \cdot P_{\mathrm{DGmL}(t)}^{\mathrm{I}} \leq P_{\mathrm{DG}(t)}^{\mathrm{I}} \leq X_{\mathrm{DG}(t)}^{\mathrm{I}} \cdot P_{\mathrm{DGML}(t)}^{\mathrm{I}}, I \in \Omega_{D G}^{d}
$$

The upstream supplier maximum limit in each period $t$ regarding active power and reactive power can be formulated as:

$$
X_{\mathrm{S}(t)}^{\mathrm{S}} \cdot P_{\mathrm{SmL}(t)}^{\mathrm{S}} \leq P_{\mathrm{S}(t)}^{\mathrm{S}} \leq X_{\mathrm{S}(t)}^{\mathrm{S}} \cdot P_{\mathrm{SML}(t)}^{\mathrm{S}} \quad \forall t, \forall S
$$

\section{3) Energy Storage System}

$X_{\mathrm{ESS}(t)}^{\mathrm{E}}+Y_{\mathrm{ESS}(t)}^{\mathrm{E}} \leq 1 \quad \forall t, \forall E$

The maximum battery balance for each ESS can be formulated as:

$$
\begin{aligned}
E_{\mathrm{S}(t)}^{\mathrm{E}} & =E_{\mathrm{S}(t-1)}^{\mathrm{E}}+ \\
& \eta_{c}^{\mathrm{E}} \cdot P_{\mathrm{C}(t)}^{\mathrm{E}} \cdot \Delta t-\frac{1}{\eta_{\mathrm{d}}^{\mathrm{E}}} \cdot P_{\mathrm{D}(t)}^{\mathrm{E}} \cdot \Delta t \quad \forall t, \forall E
\end{aligned}
$$

The maximum discharge limit for each ESS can be represented by:

$$
P_{\mathrm{D}(t)}^{\mathrm{E}} \leq P_{\mathrm{DL}(t)}^{\mathrm{E}} \cdot X_{\mathrm{ESS}(t)}^{\mathrm{E}} \quad \forall t, \forall E
$$

The maximum charge limit for each ESS can be represented by:

$P_{\mathrm{C}(t)}^{\mathrm{E}} \leq P_{\mathrm{CL}(t)}^{\mathrm{E}} \cdot Y_{\mathrm{ESS}(t)}^{\mathrm{E}} \quad \forall t, \forall E$

The maximum battery capacity limit for each ESS can be represented by:

$$
E_{\mathrm{S}(t)}^{\mathrm{E}} \leq E_{\mathrm{BC}}^{\mathrm{E}} \quad \forall t, \forall E
$$

Minimum stored energy to be guaranteed at the end of period $t$ can be represented by:

$$
E_{\mathrm{S}(t)}^{\mathrm{E}} \geq E_{\mathrm{mC}(t)}^{\mathrm{E}} \forall t, \forall E
$$

\section{4) Electric Vehicles}

Battery balance for each EV. The energy consumption for period $t$ travel has to be considered jointly with the energy remaining from the previous period and the charge occurred in the period:

$$
E_{\mathrm{S}(t)}^{\mathrm{V}}=E_{\mathrm{S}(t-1)}^{\mathrm{V}}-E_{\mathrm{T}(t)}^{\mathrm{V}}+\eta_{c}^{V} \cdot P_{\mathrm{C}(t)}^{\mathrm{V}} \cdot \Delta t \quad \forall t, \forall V
$$

When connected to the grid the vehicle cannot charge more than the admissible safety rate. The charge limit for each EV considering battery charge rate can be formulated as: 


$$
P_{\mathrm{C}(t)}^{\mathrm{V}} \leq P_{\mathrm{CL}(t)}^{\mathrm{V}} \quad \forall t, \forall V
$$

Another important aspect is the minimum stored energy to be guaranteed at the end of period t. This can be seen as reserve energy (fixed by the EVs' users or estimated by the operator) that can be used for regular travel or an unexpected trip in each period $t$ :

$$
E_{\mathrm{S}(t)}^{\mathrm{V}} \geq E_{\mathrm{mC}(t)}^{\mathrm{V}} \quad \forall t, \forall V
$$

\section{5) Demand Response}

Load demand response program, namely the direct load control program, can be formulated as:

$$
P_{\mathrm{LDR}(t)}^{\mathrm{L}} \leq P_{\mathrm{LDRML}(t)}^{\mathrm{L}} \cdot X_{\mathrm{DR}(t)}^{\mathrm{L}} \quad \forall t, \forall L
$$

The maximum duration limit of DR event can be formulated as:

$$
\sum_{t=1}^{T} X_{\mathrm{DR}(t)}^{\mathrm{L}} \leq P_{\mathrm{LDRMT}}^{\mathrm{L}} \quad \forall t, \forall L, \forall z
$$

\section{6) Market}

The market bids are constrained by (16) and (17), namely maximum and minimum energy sale:

$$
P_{\mathrm{S}(t)}^{\mathrm{M}} \leq P_{\mathrm{BSML}(t)}^{\mathrm{M}} \quad \forall t, \forall M
$$

$$
P_{\mathrm{S}(t)}^{\mathrm{M}} \geq P_{\mathrm{BSmL}(t)}^{\mathrm{M}} \quad \forall t, \forall M
$$

\section{Case study}

The proposed methodology is tested using a case study that intends to represent residential buildings in a microgrid (MG). The main goal is to obtain the minimum cost while supplying the required demand of the building. The case study uses data collected from 2 residential buildings.

Due to confidentiality reasons, the detailed content of the data used in this case study will not be shown. Figure 1 depicts the total consumption and DG production profile for this case study.

The MG operator has to fully dispatch all the power generation from DG units based on renewable sources (PV). Analysing Figure 1, the power generation from DG can supply all the consumption, but in hours without solar radiation, the aggregator will require to acquire energy from external suppliers outside of the MG.



Fig. 1. Consumption versus total DG generation.

The building MG is connected to the main grid through a medium voltage/low voltage Transform. The distribution transformer is the connection point of electrical energy between the MG operator and external suppliers.

Table I presents the data of the energy resources that are managed by the building operator and the bid coefficients, expressed in monetary unit per $\mathrm{kWh}$, the maximum power limits, and the location of resources. The price of PV panels and storage units has a price equal to zero because they are endogenous resources of the building operator. On the other hand, the operator has to remunerate the external supplier. The building operator will receive an incentive if it accepts the DR program (reduce the total consumption, at maximum until 30\%).

Table I. - Energy Resource Data

\begin{tabular}{lccc}
\hline Energy Resources & $\begin{array}{c}\text { Availability } \\
(\mathbf{k W})\end{array}$ & $\begin{array}{c}\text { Prices } \\
(\mathbf{m} . \mathbf{u} . / \mathbf{k W h})\end{array}$ & Units \\
& $\mathbf{m i n}-\mathbf{m a x}$ & $\mathbf{m i n}-\mathbf{m a x}$ & \\
\hline Photovoltaic & $0-209.10$ & 0.00 & 1 \\
\hline External Supplier & $0-162.00$ & $0.12-0.17$ & 1 \\
\hline Storage Charge & $0-9.00$ & 0.00 & 3 \\
\hline Storage Discharge & $0-9.00$ & 0.00 & 3 \\
\hline Electric Vehicle Charge & $0-15.00$ & 0.00 & 3 \\
\hline Load & $117.88-150.46$ & 0.00 & 2 \\
\hline Demand Response & $7.88-10.31$ & $0.05-0.12$ & 1 \\
\hline
\end{tabular}

The MG operator requires the use of other resources (external suppliers, DR programs, discharge from storage) to support the load between periods 1 to 9 and between periods 16 to 24 . In the remaining periods, the excess of generation from endogenous resources can be used to charge storage/EVs or to sell energy to the electricity market. The EVs parked in the parking lot of the buildings were also considered in the management of the MG. The charging of their batteries can be controlled by the MG operator. The same control stands for the storage systems.

For this case study, the robust technic obtained an optimal solution with a cost of 46.60 m.u. The methodology took around 15 seconds to find the optimal solution. The case study has been tested in a machine with one Intel ${ }^{\circ} \quad$ Xeon ${ }^{\circledR} \quad$ E5-2620v2 - $2.10 \quad \mathrm{GHz}$ processor, with 12 cores, 16GB of Random-AccessMemory (RAM), and Windows 10 Education. Fig. 2 depicts the energy scheduling result. 


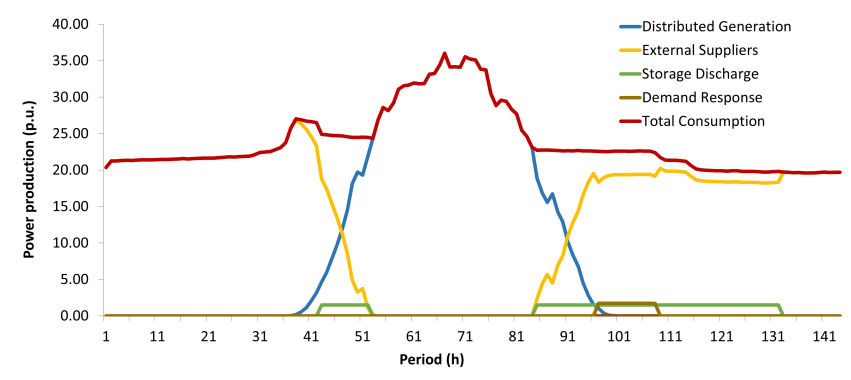

Fig. 2. Optimal Resource Scheduling.

The results show the impact of the DG according to the photovoltaic generation profile (only one DG technology used). The storage discharge is a resource used between $15 \mathrm{~h}$ and $22 \mathrm{~h}$ because in these periods the PV production is small or null and in the previous periods, there was significant use of storage charge justified by the high penetration of PV. The demand response event has a limit of 2 hours per day and was used in peak consumption periods of the grid. In the rest of the periods, the consumption is fully supported by the external supplier. Figure 3 depicts the percentage of each resource in the optimal resource scheduling.

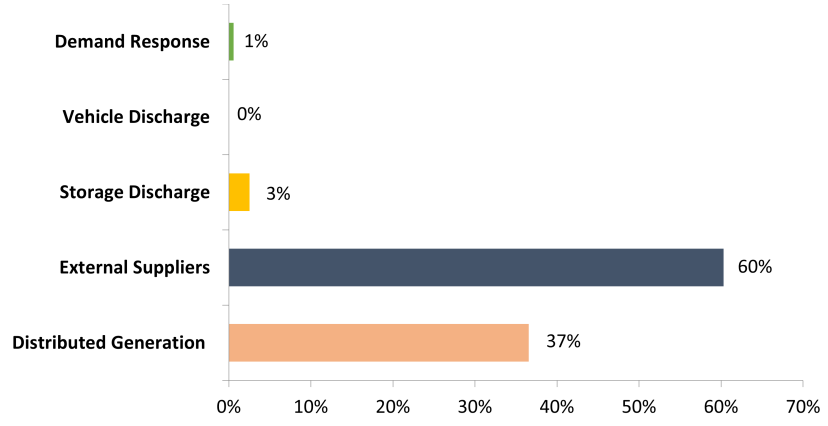

Fig. 3. Percentage of each resource in the optimal energy scheduling.

Through Figure 3 it is possible to see that the DG contributes $37 \%$ of the total generation. $60 \%$ is given by the external suppliers, while storage discharge and demand response contribute with $2 \%$ and $1 \%$, respectively.

Figure 4 presents the load diagram, which contains the loads' consumption, EVs and storage charge, and energy sale to the electricity market.

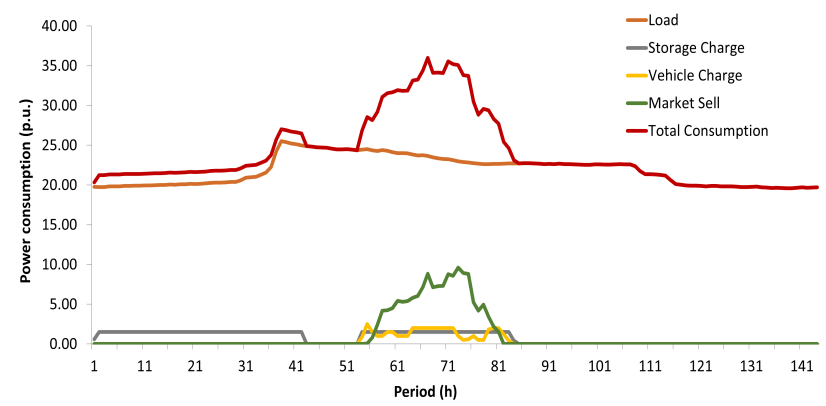

Fig. 4. Optimal resource scheduling.

Analysing Figure 4, the MG operator can sell energy in the electricity market between periods 10 and 14. In these periods, there is an excess of PV generation. In the same periods, the excess of PV generation is used to charge the EVs and storage. Regarding this, the storage charging is also carried out in periods when the MG operator can buy energy to the external suppliers with a cheaper price, corresponding essentially tonight periods ( $1 \mathrm{~h}-7 \mathrm{~h})$.

Figure 5 depicts the percentage of each resource in the consumption schedule. The total power consumption was divided into $92 \%$ for the consumption in load points, $1 \%$ for charging the EVs, $4 \%$ for the sale of generation excess to the electricity market and, $3 \%$ for storage charge.

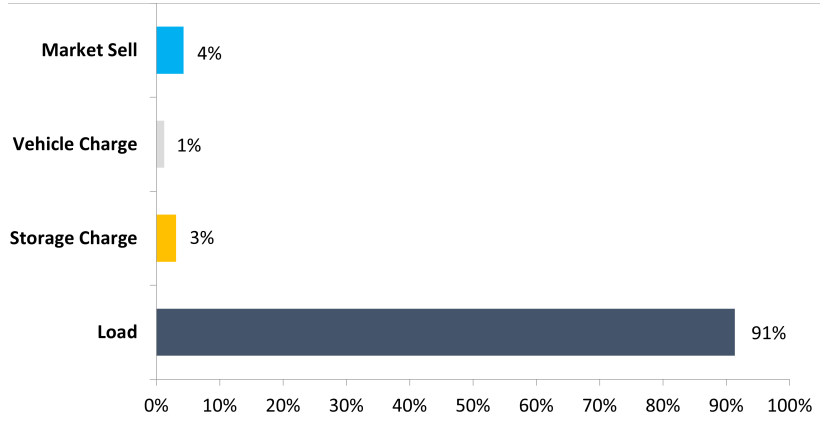

Fig. 5. Percentage of each resource in the consumption schedule.

\section{Conclusions}

This paper presented intelligent energy management for residential buildings in a microgrid. The energy resource management model includes demand response programs, electrical vehicles, energy storage systems, and photovoltaic panels.

The main goal is to obtain optimal energy resource scheduling. The formulated problem represents mixedinteger linear programming and is implemented in TOMLAB, which is an advanced optimization toolbox for MATLAB, using a CPLEX solver. The proposed problem has an objective function to minimize the total energy bill cost. Considering the processing time, the model developed in this work can be a useful method to obtain a quick solution for the next day, allowing that the MG operator solves the energy resource scheduling problem.

\section{Acknowledgment}

This work has received funding from FEDER Funds through COMPETE program and from National Funds through FCT under the project BENEFICE-PTDC/EEI$\mathrm{EEE} / 29070 / 2017$ and UIDB/00760/2020 under CEECIND/02814/2017 grant.

\section{References}

[1] G. Brusco, A. Burgio, D. Menniti, A. Pinnarelli, and N. Sorrentino, "Energy management system for an energy district with demand response availability," IEEE Trans. Smart Grid, vol. 5, no. 5, pp. 2385-2393, 2014.

[2] Park, Y. Yoon, S. Cho and S. Choi, "Prosumer Energy 
Management Considering Contract With Consumers Under Progressive Pricing Policy," in IEEE Access, vol. 8, pp. 115789-115799, 2020, doi: 10.1109/ACCESS.2020.3004643.

[3] J. Guerrero, F. Blaabjerg, T. Zhelev, K. Hemmes, E. Monmasson, S. Jemei, M. Comech, R. Granadino, and J. Frau, "Distributed Generation: Toward a New Energy Paradigm," IEEE Ind. Electron. Mag., vol. 4, no. 1, pp. 5264, Mar. 2010.

[3] J. Ye, Q. Xie, Y. Xiahou, and C. Wang, "The research of an adaptive smart home system," in 2012 7th International Conference on Computer Science \& Education (ICCSE), 2012, pp. 882-887.

[4] J. Jaihar, N. Lingayat, P. S. Vijaybhai, G. Venkatesh and K. P. Upla, "Smart Home Automation Using Machine Learning Algorithms," 2020 International Conference for Emerging Technology (INCET), Belgaum, India, 2020, pp. 1-4, doi: 10.1109/INCET49848.2020.9154007.

[5] P. Faria and Z. Vale, "Demand response in electrical energy supply: An optimal real time pricing approach," Energy, vol. 36, no. 8, pp. 5374-5384, 2011.

[6] J. Y. Son, J. H. Park, K. D. Moon, and Y. H. Lee, "Resource-aware smart home management system by constructing resource relation graph," IEEE Trans. Consum. Electron., vol. 57, no. 3, pp. 1112-1119, 2011.

[7] M. Rastegar, M. Fotuhi-Firuzabad, and H. Zareipour, "Home energy management incorporating operational priority of appliances," Int. J. Electr. Power Energy Syst., vol. 74, pp. 286-292, 2016.

[8] M. Pipattanasomporn, M. Kuzlu, and S. Rahman, "An Algorithm for Intelligent Home Energy Management and Demand Response Analysis," IEEE Trans. Smart Grid, vol. 3, no. 4, pp. 2166-2173, Dec. 2012.
[9] P. Chavali, P. Yang, and A. Nehorai, "A Distributed Algorithm of Appliance Scheduling for Home Energy Management System," IEEE Trans. Smart Grid, vol. 5, no. 1, pp. 282-290, Jan. 2014.

[10] Zhuang Zhao, Won Cheol Lee, Yoan Shin, and KyungBin Song, "An Optimal Power Scheduling Method for Demand Response in Home Energy Management System," IEEE Trans. Smart Grid, vol. 4, no. 3, pp. 1391-1400, Sep. 2013.

[11] M. Kuzlu, M. Pipattanasomporn, and S. Rahman, "Hardware Demonstration of a Home Energy Management System for Demand Response Applications," IEEE Trans. Smart Grid, vol. 3, no. 4, pp. 1704-1711, Dec. 2012.

[12] W. Li, T. Logenthiran, W. L. Woo, V.-T. Phan, and D. Srinivasan, "Implementation of demand side management of a smart home using multi-agent system," in 2016 IEEE Congress on Evolutionary Computation (CEC), 2016, pp. 2028-2035.

[13] F. Zahra, R. Sérgio, S. J. ao, L. Fernando, V. Zita, G. Antonio, L. J. Rodrigo, A mixed binary linear programming model for optimal energy management of smart buildings, Energies 13(7) (2020) 1719. doi: https://doi.org/10.3390/en13071719.

[14] Zahra Foroozandeh, Sérgio Ramos, João Soares; Zita Vale. 2021. "Energy Management in Smart Building by a Multi-Objective Optimization Model and PascolettiSerafini Scalarization Approach". Processes 9, no.2:257. January 2021.

[15] TOMLAB, “TOMLAB optimization,” 2016. [Online]. Available: http://tomopt.com/tomlab/about/.

[16] MathWorks, "MATLAB - The Language Of Technical Computing," 2016. [Online]. Available: http://www.mathworks.com/products/matlab/. 